\title{
A Brief Genealogy of Hanmai
}

\section{Ge Zhang and Jian Xu}

\section{(2) OpenEdition}

\section{Journals}

\section{Electronic version}

URL: http://journals.openedition.org/chinaperspectives/9528

DOI: 10.4000/chinaperspectives.9528

ISSN: 1996-4617

\section{Publisher}

Centre d'étude français sur la Chine contemporaine

\section{Printed version}

Date of publication: 1 September 2019

Number of pages: 63-68

ISSN: 2070-3449

\section{Electronic reference}

Ge Zhang and Jian Xu, «A Brief Genealogy of Hanmai », China Perspectives [Online], 2019-3 | 2019,

Online since 01 September 2019, connection on 22 December 2020. URL : http://

journals.openedition.org/chinaperspectives/9528; DOI : https://doi.org/10.4000/chinaperspectives. 9528

(c) All rights reserved 


\title{
A Brief Genealogy of Hanmai
}

\author{
GE ZHANG AND JIAN XU
}

\section{Introduction}

$H$ anmai 喊麥, literally "shouting [at] a microphone," first came to public attention and scrutiny as a distinct sound gaining both popularity and notoriety in 2015, when livestreaming platforms such as YY (which launched as a voice chat client in 2008) were growing exponentially. ${ }^{1}$ Contemporary hanmai is therefore predominantly associated with livestreaming media. ${ }^{2}$ However, its origin can be traced much further back. The sound culture can be linked to the broader context of market reform and the emergence of disco music in the 1990s, as well as to the evolution of Northeastern (Dongbei 東北) folk culture during the same period. Dongbei spoken word art has fundamentally shaped the lyrical structure and presentation of hanmai, while its lyrical content has shifted over time from a dance culture filled with hedonist desires in the late 1990s and early 2000 s to a contemporary livestreaming culture of venting frustration due to unfulfilled desires. Moreover, socio-technologically speaking, hanmai culture started in the form of commercial sales of pirate mixtape CDs, then migrated to QQzone (Tencent's version of personal webspace similar to Myspace) throughout the 2000s, re-invented itself via Internet subculture on early video portals such as Acfun as well as popular web fiction, and finally (re)emerged on YY as the contemporary reiteration of hanmai. This paper aims to map a genealogy of hanmai, including the divergences, parallels, and reiterations of this specific style of sound in Chinese society from the 1990s onwards.

\section{Discotheques and revitalised Dongbei folk culture}

Hanmai's musical origin can be traced back to China's discotheques and dance halls of the late 1990s in the context of China's "revolution of consumption" (Davis 2000). The history of disco dance clubs from the 1990s to 2000s in Shanghai is well documented by Andrew Field (2008) and James Farrer (2000). Shanghai discotheques (disike 迪斯科) emerged as "large, cavernous, dark, and simply decorated" (Field 2008: 21) "free-flowing zones of interaction among clubbers from different backgrounds" (Field and Farrer 2018: 128). Compared to the partnered dance halls of the 1980s (which later developed into collectivist square-dancing venues), discotheques were for individual dancing to various genres of electronic music. In first-tier cities such as Shanghai, discos were segregated between the local Shanghainese crowd visiting different clubs and the more international crowd of expats, overseas returnees, Hongkongers, and Taiwanese. For example, in contrast to Shanghai's pioneering D.D., a club that played up-to-date club music and invited foreign DJs, most local discos "tended to be a mixture of mainstream American pop, Cantopop and Taiwanpop, the music favoured by Chinese" (Field 2008: 23). In

1. We use the term sound because it is more neutral than music and therefore circumvents contemporary debates over whether hanmai constitutes music.

2. Javier C. Hernández, "Ranting and Rapping Online in China, and Raking in Millions," The New York Times, 15 September 2017, https://www.nytimes.com/2017/09/15/world/asia/china-li-tianyoulivestream.html (accessed on 13 March 2019).

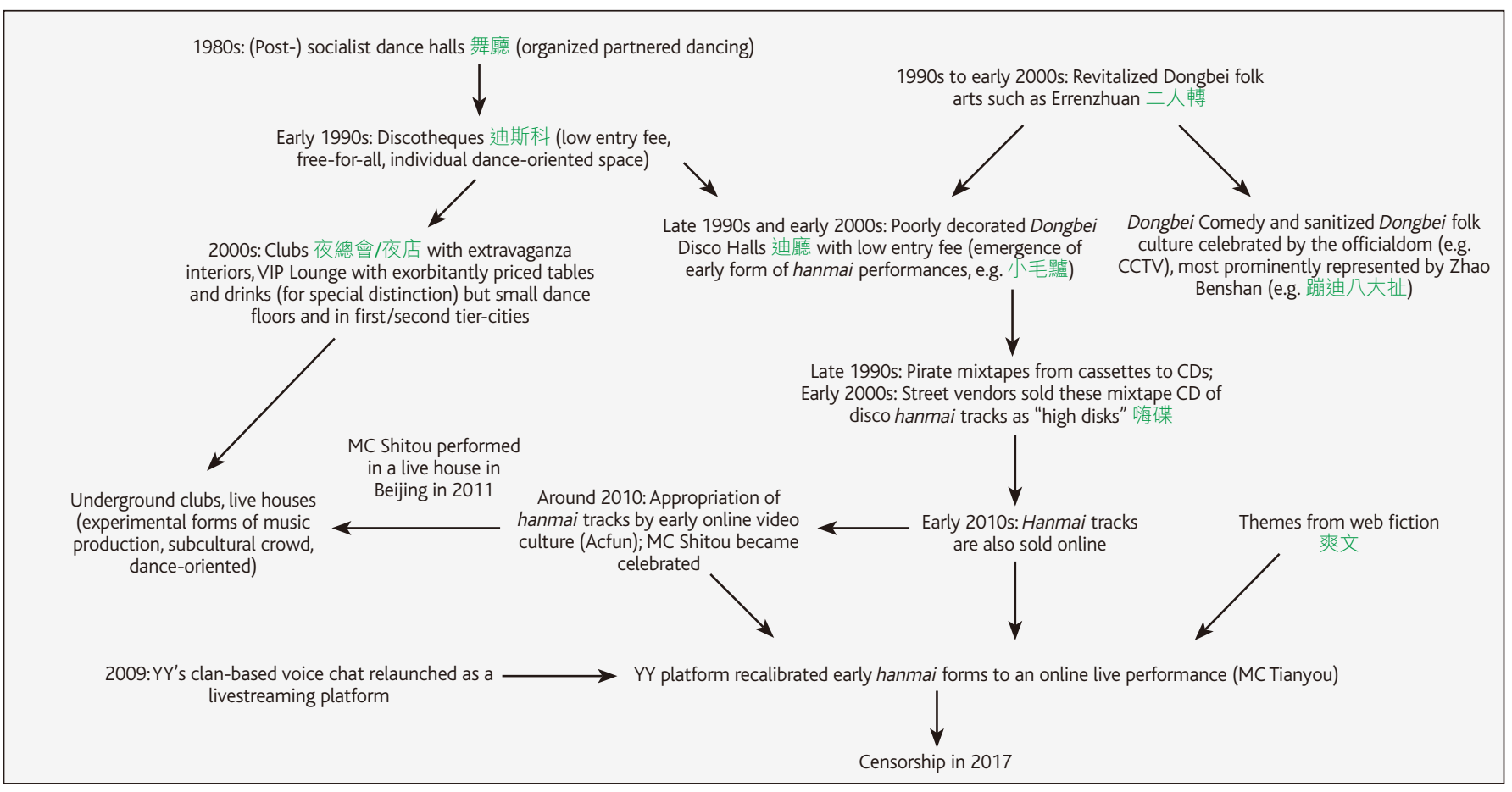

Figure 1. Mapping the genealogy of hanmai by the authors 
the late 2000s, when mainstream nightlife shifted toward a new generation of extravagant VIP clubs that relied on selling expensive drinks and exclusive lounge/tables rather than entry tickets, Chinese mainstream discotheques and clubs were rarely innovative in their music production and curation and did not invite progressive DJs. Underground clubs existed only marginally in Shanghai and Beijing from around 2010, when they began to expand into second and third-tier cities as recognisable electronic music labels, such as Shanghai's Genome 6.66Mbps, and gained popularity. ${ }^{3}$

The downward transfer of imported music and cultural objects from firsttier Chinese cities to smaller cities often involves a time lag, and does not follow an exact replication but rather a re-iteration or misinterpretation (either unwittingly or intentionally due to different local constraints and advantages) that usually coalesces with the folk cultures of early adopters in that region, sometimes rather creatively. The emergence of discotheques in the rust belt of the declining industrial Dongbei region is such a case. The large waves of layoffs (xiagang下崗) and closures of state-owned factories in the first half of the 1990s razed the glorified lives of workers to the ground, and the obliteration of both stable income and the value system of the Maoist past left people adrift in the new "free market" (Liu 2018). Discotheques provided a novel venue for indulging in consumerism and affordable escapism in the industrial cities: the disenfranchised lower-class youths (sometimes even the middle-aged) prevailed in these poorly decorated disco halls.

A simultaneous process was the rebuilding of Dongbei folk culture after the collapse of working-class culture in the 1990s. One example is the transformation of workers' cultural palaces (gongren wenhuagong 工人文化 宮) from the core of working-class leisure life into the unfamiliar (to urban residents at the time) "Two-people Rotation" (Errenzhuan 二人轉) theatres (Liu 2018). This reintroduction of Dongbei folk culture, and in particular Errenzhuan comedy skits, into city leisure life (especially in Shenyang) helped revitalise the entertainment industry in the region. Its proponents such as Zhao Benshan (趙本山) also promoted this rebranded folk culture on China Central Television from the late 1990s, and on the Internet in the following decade. This process of remaking folk culture appropriate for the political mainstream (e.g. China Central Television) is also a process of sanitising the content (e.g. lyrics) and reinventing or "modernising" (in official terms) the form with various borrowed elements. In Zhao Benshan's and others' performances of Dongbei folklore, vulgarity (su 俗) becomes legitimate in its appeal to the common people, which can be seen as a continuation of the agrarian Maoist ideal.

Errenzhuan - specifically its improvised spoken rhymes as opposed to its dance moves - was introduced to discotheques in the late 1990s. In the early 2000s, Sun Xiaobao's "Eight Doggerels with Disco Drum Beat" 4 (Bengdi badache 䠒迪八大扯) was produced by the Errenzhuan theatre company, Shenyang Samon Cultural Development Company, and was widely distributed in pirate VCDs at the time. The prototypical tropes of hanmai are evident in Sun's performance - a disco mixtape of background beats and a predictable lyrical structure of five characters in each verse/ metrical line. The song was a lengthy commentary on various occupations (e.g. celebrities, drivers, and poor/unemployed people) and ranking people in each profession from level one to eight according to their quality of life. The video was produced to imitate a television studio with a live audience, and since it was released via official channels, it was obviously approved by the censors.

The reasons behind the merging of imported electronic music and a revitalised folk art can be speculated: (1) Dongbei lacked its own electronic music production and DJ scene in the mid-to-late-1990s, as electronic music was just being introduced to the region from first-tier cities like Beijing and Shanghai; (2) Errenzhuan and the associated folk arts of spoken word may have been more appealing to the local audience or perhaps a spontaneous experiment by early organisers in the disco scene.

In large Chinese discos, rather than a DJ booth, there was often a stage where performers "rapped" either improvised or written lyrics to disco beats with spinning strobe lights in the background. We hesitate to call these performers DJs, as they do not produce or curate the music but purchase mixtapes from various sources - as we will discuss later. This format of having someone on the stage addressing the dancing crowd - a form of MC (Microphone Controller) - can be seen as another aspect of (mis)interpreting conventional DJ practice. While the origins of the $M C$ are in the hip hop tradition, in many Chinese contexts $M C$ refers to the specific role of hyping up the crowd, whether in a club, at a wedding, or on a YY channel (to be discussed later), and it can even be synonymous with the term 主持人 (zhuchiren, a venue/event host).

Compared to the earlier example of "Eight Doggerels with Disco Drum Beat" and state television's adoption of Errenzhuan, performances in the disco halls were not sanitised; the sexual/erotic tropes of Dongbei folk music were not shunned but rather amplified with the arrival of new profane themes such as consumerism and experiments with drugs and promiscuity. For example, one such track, named "Little Donkey" (Xiaomaolü 小毛驢), emerged in the late 1990s and was popular into the early 2000s. The main beats derive from Alex To's popular hit "Undress" (Tuodiao 脱掉). The track begins with the lines adapted from a nursery rhyme of the same name but escalates into the following:

\section{學習雷鋒好榜样, 雷鋒吃了偉哥他也和你一樣!}

Learn from Lei Feng the good example, Lei Feng is the same as you if he takes Viagra! ${ }^{6}$

\section{學習雷鋒好榜樣, 雷鋒吃了搖頭丸他也和我一樣!}

Learn from Lei Feng the good example, Lei Feng is the same as me if he takes Ecstasy!

\section{床前明月光, 地上鞋兩雙}

Moonlight before my bed, two pairs of shoes on the floor.

床上狗男女, 其中就有你!

Adulterers on the bed, one of them is you!

\section{春眠不覺曉, 處處性騷擾.}

Dream in Spring never breaks, sexual harassment is everywhere. 夜來叫床聲, 處女變大舅!

Moan coming in the evening, virgins become old women!

3. Due to limited space, we cannot elaborate on the development of underground clubs in various Chinese cities after 2010 (e.g. OIL Club in Shenzhen and the Boring Room in Xi'an). For a history of the early Chinese scene of electronic music, refer to Philipp Grefer, "Disco(s), Techno and the EDM Storm: A Brief (and Personal) History of Electronic Music in China," The Beijinger, 6 November 2016, https://www.thebeijinger.com/blog/2016/11/04/discos-technoand-edm-storm-brief-and-personal-history-electronic-music-china (accessed on 13 March 2019)

4. See Sun Xiaobao 孫小寶 performing "Eight Doggerels with Disco Drum Beat" on Youtube: https://www.youtube.com/watch?v=vV_zPxfPr_Y (accessed on 13 August 2019)

5. Online version accessible here: http://www.dj308.com/play/275.html (accessed on 13 March 2019).

6. Lei Feng 雷鋒 (1940-1962) was a peace-time soldier in the People's Liberation Army (PLA) and is one of the most influential role models in Maoist China. In 1963, the year after his death, Mao Zedong called on Chinese to from Lei Feng's selflessness, modesty, loyalty to the Chinese Communist Party, and service to the people. 


\section{The online circulation of hanmai tracks: From haidie to MC Shitou}

The above track was not only performed live in discotheques but also circulated on cassettes. ${ }^{7}$ Later, with the emergence of CDs and the rampant piracy in the 2000s, hanmai tracks were sold on "chained and burnt" (chuanshao 串燒) mixtapes or CD reproductions of Canto/Mandarin pop songs and classic disco tracks from the 1980s. These pirate (V)CDs were sold by street vendors rolling a trolley equipped with an amplifier blasting "high discs for sale" (mai haidie 賣烸碟). The CDs were very cheap and especially welcomed by drivers, as modified car stereo speakers were in fashion in the early 2000s. Eventually these marginal commercial activities moved online, and around 2010, hanmai tracks were being sold on QQzone, Taobao, and other websites. For example, hanmai veteran MC Xiexiaoyu 謝小宇 recounted that his first income from practicing hanmai was a mixtape CD he sold for $20 \mathrm{Qbi}$ (a virtual currency that can be used on Tencent platforms) in 2012. ${ }^{8}$ In 2013, the website Hanmai DJ (http://www.hanmaidj.com/) was launched as a hub for publishing hanmai tracks.

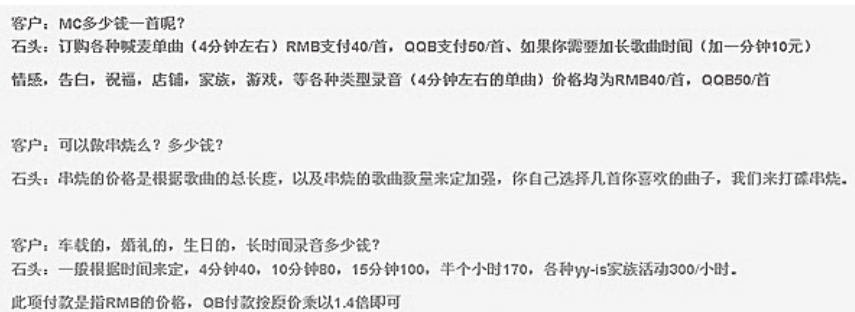

Client: How much is a MC track?

Shitou: If you book any sort of hanmai track (around 4 minutes), 40 RMB per track, or $50 \mathrm{QQB}$ (QQ's virtual coin). If you want longer than that (one extra minute for $10 \mathrm{RMB}$ ). Love, confession, blessing, commercial, family, video games, and so on, all these genres of recordings (a single track of 4 minutes) will cost 40 RMB per track, $50 \mathrm{QQB}$ per track.

Client: Can you do mixtape? How much?

Shitou: The price of a mixtape will depend on the length of each track, and the number of tracks. You can pick your own favourite, we will do the mixing.

Client: Car music, wedding, birthday party, how much for a long recording for these occasions? Shitou: It will depend on the time, 4 minutes 40 RMB, 10 minutes 80 RMB, 15 minutes 100 $\mathrm{RMB}, 30$ minutes $170 \mathrm{RMB}$, and various YY-IS clan activities $300 \mathrm{RMB}$ per hour.

If you want to pay in $\mathrm{QQB}$, please pay 1.4 times the original $\mathrm{RMB}$ price.

Figure 2: MC Shitou's QQzone outlines the details of the genres and prices of remixing hanmai tracks for various purposes. Image extracted from https://site.douban.com/ym1986/widget/notes/440643/ note/156848545/ (accessed on 13 March 2019). Translation by authors.

Before 2010, the first space for electronic hanmai production was not home studios but rather Internet cafés. Early hanmai producers first started remixing tracks and producing hanmai tracks in an Internet café in 2008, with a low-resolution webcam and a headset microphone. Until the second half of the 2010s, when livestreaming hanmai grew in popularity, the commercial activities of an MC were limited to two channels: selling tracks online and performing live in discos and clubs - but only the mainstream clubs (as opposed to the VIP-based clubs and discos outlined earlier). Luzhou-based MC Shitou 石頭 was the first (and possibly the only) hanmai DJ to make a subcultural breakthrough on the video portal Acfun. In 2010, MC Shitou's hanmai videos were discovered by Acfun remix video creators, and his hanmai track "Love debt" (Qing zhai 情債), based on Zhitao's track, was an instant hit. Acfun at the time was at the frontline of Chinese Internet subculture that would absorb and appropriate any aesthetically provoking materials and aesthetics. In Acfun's video clips, MC Shitou had the pronounced look of a Shamate 殺馬特 ${ }^{9}$ - exaggerated hair style and colour, an unbuttoned white shirt, slim-cut blazer - and his voice had a distinct style of mispronouncing English phrases "here we go" as 黑喂狗 (hei wei gou, literally "Black Eat Dog"). The danmu 彈幕 (bullet screen) comments on the video also had a specific visual style. In an act of appropriating the stigmatised aesthetic of the rural and the grotesque, Acfun viewers utilised the comments to simulate the sticker advertisements that are omnipresent on the poles and stairs in suburban and rural China, such as "massive sale of sanitary pads, please contact 5564878," "assassin for hire, contact 84523," "coffin sale, contact 484854," "change your fate, contact 741165." MC Shitou's rural style was not ridiculed but celebrated as a distinct aesthetic.

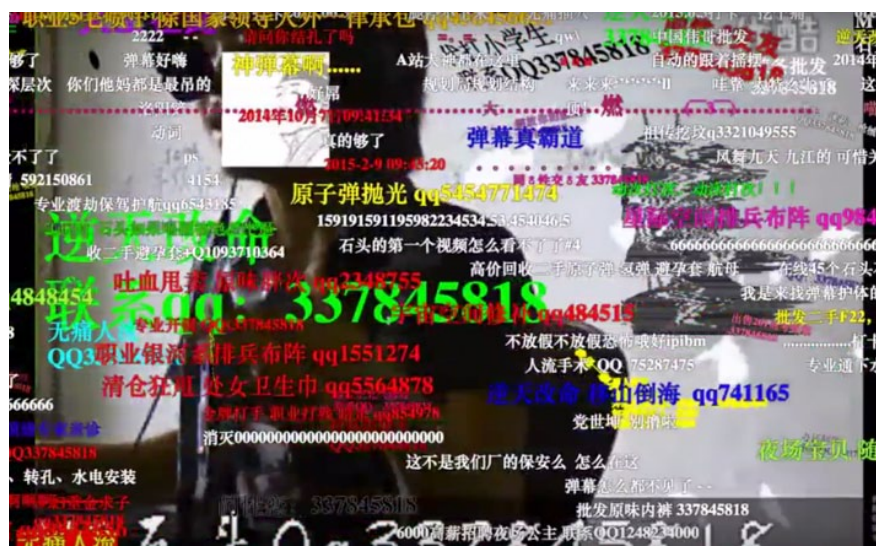

Figure 3. MC Shitou's video Qingzhai on Acfun.com. Screenshot taken by the authors.

This initial success in the new territory of Internet subculture also prompted invites from live venues in the underground scene. In 2011, MC Shitou was invited to perform at Yugong Yishan, one of Beijing's oldest live houses for indie bands and various genres of non-mainstream music. This event even received media coverage from Beijing Evening News..$^{10}$

For some music pundits, MC Shitou's appearance at the avant-garde music venue was an insult to the enshrined subcultural space. ${ }^{11}$ However, MC Shitou's presence at this event was a point in history when the (supposedly) avant-garde scene and an amateurish, displaced producer - in that MC Shitou had poor DJ skills and limited knowledge of electronic music

7. 008 Tangzong 008 糖總, “喊麥自古以來就是東北的文化傳統” (Hanmai zigu yilai jiushi Dongbei de wenhua chuantong, Hanmai has its origin in the traditional culture of Northeast China), Sohu, 7 November 2017, http://www.sohu.com/a/202920519_635871 (accessed on 13 March 2019).

8. Liu Youxiang 劉悠翔, “城市套路深我不回“農村”他們靠喊麥為生” (Chengshi taolu shen wo bu hui "nongcun", Urban life is hypocritical and complicated but I don't want to go back to village home), Nanfang Zhoumo, 23 July 2016, http://www.infzm.com/content/118469 (accessed on 13 March 2019).

9. Shamate is a Chinese transliteration of the English word "smart." It refers to a subculture characterised by glam rock outfits, outrageous hairstyles, and vampire (emo-ish) makeup among rural and migrant young people in China. Shamate enthusiasts formed a large online community on QQzone which made shamate a popular cyberculture. More details about the socialcultural origins and performance of the culture can be found here: https://www.sixthtone.com/ news/1112/how-shamate-devolved-from-urban-to-underclass-fashion; http://www.sixthtone. com/news/1133/death-of-a-subculture-the-life-of-a-former-shamate (accessed on 18 March 2019).

10. “"喊麥'石頭征服北京夜店” ("Hanmai" Shitou zhengfu Beijing yedian, MC Shitou conquers Beijing club), Beijing Wanbao, 6 November 2011, http://www.chinanews.com/yl/2011/1106/3440435.shtml (accessed on 18 March 2019).

11. Yaogunke 搖滾客, “從殺馬特 MC 石頭, 到貴族 MC 天佑, 喊麥就是個天大的笑話! ” (Cong shamate MC Shitou, dao guizu MC Tianyou, hanmai jiushi ge tianda de xiaohua, From Shamate MC Shitou to Aristocrat MC Tianyou, Hanmai is massive joke!), Jam, 8 April 2017, http://www. jammyfm.com/p/128400.html (accessed on 13 March 2019). 


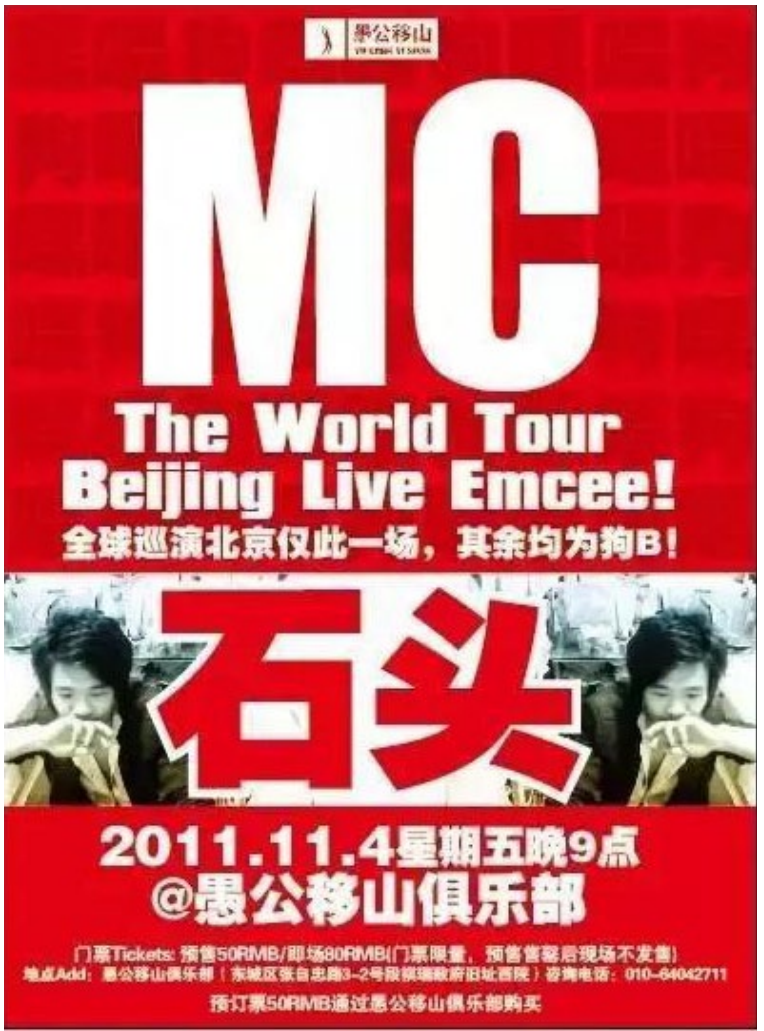

Figure 4. The poster for MC Shitou's show at Yugong Yishan in 2011.

- converged in the iconic Beijing Live house. An ardent audience, including the celebrated rock star Cui Jian, was there not to ridicule MC Shitou but to celebrate the aesthetics of vulgarity created around him (but not necessarily intended by him). ${ }^{12}$ MC Shitou's decline in popularity around 2014 was due to his failure to adapt to the rise of livestreaming platforms, as well as the fact that he was not in control of the unique and subversive aesthetics that were associated with him. The danmu aesthetics and reproduction of his mixtapes on Acfun were not necessarily his intentions, and his hanmai tracks became absorbed by an Internet subculture. ${ }^{13}$ If the explicit vulgarity in "Little Donkey" was the unfiltered emotion of the ordinary people, the subversion of the subcultural adaptations of MC Shitou's hanmai video lay in a secondary (or even third, considering hanmai tracks are mostly remixes plus parodic lyrics of other pop/folk songs) appropriation circulated online in - relatively speaking - marginal spaces. While MC Shitou failed in transitioning to livestreaming platforms, Dongbei-based MC Tianyou 天佑 thrived in the livestreaming scene.

\section{Tianyou: The fantasy and reality of hanmai Jianghu}

Before 2009, YY was a voice chat platform for MMOG (massively multiplayer online games) players and guilds to organise/communicate in-game events such as raids. YY's channels attracted a variety of interest groups, most prominently karaoke hobby groups. These channels formed the community base for YY's rebranding as a livestreaming platform from 2010 onwards. The hosts or MCs of these voice-based channels gradually became the centre, as they became the broadcasters of livestreams - "hosting" an entire channel from thousands to tens of thousands of fans.

Hanmai's resurgence on YY recalibrated the genre in various ways. The first notable development is the lyrical content. As I have emphasised earlier, hanmai's core performativity always relied on its rhyming lyrics rather than music production. For MCs on livestreaming platforms, the work of music production/composition/curation is further reduced from the previous generation of hanmai producers such as MC Shitou. The main expertise is in the performance of hanmai itself, improvised or otherwise. Moreover, the lyrical creativity no longer relies on themes of eroticism and drugs, but incorporates web fiction as well as more contemporarily relevant social issues. Here is a snippet of MC Tianyou's cover "Cet Drunk Alone" (Yiren wo yinjiu zui - 人我飲酒醉) - originally written and produced in 2015 by MC Gao Di:

\section{敗帝王, 鬥蒼天 \\ Defeating the emperor, fighting the gods 奪得了皇位以成仙 \\ Seizing the throne, achieving immortality 豪情萬丈天地間 \\ Residing in pride between heaven and earth 我續寫了另類帝王篇 \\ I have rewritten the alternative story of becoming the Emperor. ${ }^{14}$}

Lyrically, this track imitates the basic literary elements of classic Chinese poetry, Errenzhuan, but with the fantastic tropes of Chinese online fiction (wangluo wenxue 網絡文學) - defeating the emperor, fighting against fate, comradeship in war, betrayal by betrothal. The popularity of certain genres of web novels among the mainstream audience, such as fantasy light novels on the theme of achieving immortality (xiuxian 修仙), have had significant impact on hanmai lyrics with explicit references to these themes. ${ }^{15}$ Gao (2018) argues that the pleasure of reading this genre of web novels (also apparent in the above lyrics) is in the vicarious triumph over the oppressors in "real" hierarchal society. The logic of fantasy novels such as The Coiling Dragon (Panlong 盤龍) ${ }^{16}$ is not to topple capitalism or imagine how a class society could operate in an alternative way, but to instrumentalise the process of social mobility, represented by climbing the hierarchy in the fantasy world. Continuing our earlier argument of how hanmai reiterates both a foreign musical genre (i.e., disco or electronic music) and supposedly traditional folk arts, we understand hanmai as an attempt to (re)interpret, imitate, and even caricaturise perceived high culture and historical fantasies, especially from the perspective of the archetypal Chinese male today the precariously hardworking and involuntarily celibate male whose main pastimes are web novels, mobile games, and online videos. The lyrics embody the escapist desire for another world where the protagonist can be the masculine ideal. In other words, listening to hanmai can be gratifying, and

12. MC Shitou reportedly panicked before the show as he was not familiar with the equipment available at Livehouse. See http://blog.renren.com/share/266833531/9815288490/0 (accessed on 13 March 2019).

13. A counter-example to MC Shitou is the case of Hengdunanhai 狠毒男孩, who consciously vulgarised his music for aesthetic subversion. Also, originally making music in an Internet café, he abused auto-tune software and produced hip hop tracks with obscene lyrics and a hyperbolically comedic style of performance. While Hengdunnanhai claimed he wanted to be "touching the ground energy" (jiediqi 接地 气) (i.e., be accepted by ordinary people), his music was actively subverting the paradigm of hip hop music production in China. See this interview, 18 June 2016, http://www.wooozy.cn/interview/hendunanhai/ (accessed on 13 March 2019).

14. “MC 天佑翻唱喊麥作品 '一人飲酒醉”' (MC Tianyou fanchang hanmai zuopin "yiren yinjiu zui", MC Tianyou's hanmai cover "Get Drunk Alone") on Youtube: https://www.youtube.com/ watch? $v=s N f h S z d D r a l$ (accessed on 13 August 2019).

15. The rise of fantasy light novels in China and even their influence outside of China is another topic that we cannot engage here; see Wang (2017).

16. A preview of the English translation of the novel can be found at https://www.wuxiaworld.com/ novel/coiling-dragon-preview (accessed on 13 March 2019). 
"yelling along" is an exhilarating way to let off steam.

On the livestreaming platform YY, hanmai channels assemble a very specific sociality - 江湖 (lianghu) of hanmai. Jianghu, literally "rivers and lakes," originally referred to a fantastical (under) world in Chinese martial arts (wuxia 武俠) literature (Wu 2012). Gao (2018) argues that the aforementioned web fiction genre xianxia (仙俠) is a vulgarised version of wuxia (represented by authors such as jin Yong) that instrumentalises or "technologises" (in Gao's word) ${ }^{17}$ the personal growth of the protagonist. Jianghu symbolises the warrior spirit, brotherhood, sectarianism, mentorship (between master and apprentice), and social hierarchy. The metaphor of Jianghu has been widely used to describe the "barbaric" development of China's Internet culture and digital economy in the early stages when rules, regulations, and laws were not yet established by the government (Yang 2009; Yu 2017). The hanmai Jianghu on YY thus represents the early unregulated growth of one of the earliest livestreaming platforms in China.

MC Tianyou usually livestreamed according to a fixed schedule on a daily basis. This regularity and the intimate live interactions with fans not only built the loyalty of fans but also an attention economy on YY, mediated by virtual gifts. MC Tianyou has 16 million followers on YY and can reportedly earn more than 1 million CNY every month through livestreaming. His fans called themselves "Tianyou's Army" (Youjiajun 佑家軍), which literally means to guard "the King of hanmai." His followers address him as "Big brother" (Laoda 老 大), which is a common phrase in the underworld of gangs and outcasts. Tianyou's growth from a grassroots street vendor to a celebrity has inspired thousands of young people like him to embark on their own hanmai streaming career. Some of them formally acknowledge celebrity MCs such as Tianyou, Jiuju 九局, and A'zhe 阿哲 as their "masters," giving themselves the title of apprentice to boost the viewership of their own channel. Apprentices pay high mentorship fees to be accepted by a wellknown hanmai "master."

The mentorship has further divided MC streamers and their fans into "armies" on YY. They scramble for supremacy in hanmai, making YY not just a platform but a battlefield.YY's weekly ranking of "Star of the Week" (meizhou zhixing 每周之星) has sparked the most online clan wars between various MCs' personal armies. The competition for popularity between MC streamers is an ostensible display of the amount of donations they receive from their ordinary fans and wealthy sponsors, who are flattered by livestreamers and willing to spend millions on virtual gifts to support their favourite streamers. It is a delicate skill to maintain the relationship with wealthy donors and balance this flattering relationship with an intimate connection with ordinary fans. Moreover, big name MC streamers are all affiliated with certain clans, brokers between YY and contracted streamers. In order to win the title of "Star of the Week," streamers often need generous financial support from the clans they belong to, which in turn receives a commission from the streamers' gift income and advertising.

\section{Conclusion}

The contemporary hanmai scene on $Y Y$ is far more than a genre of performance or music. It is intertwined with desires of upward mobility, celebrity-dom, financial interests, and above all the complicated sociality and ethos of Jianghu. One popular argument is that Dongbei is the origin or birthplace of hanmai, and the Jianghu of hanmai is a miniature of Dongbei society. As we have shown in this genealogy of hanmai, it certainly derived from a rebranded version of Dongbei folk culture, but the actual development is more divergent than linear. We should not enclose the entirety of hanmai within Dongbei folk culture, as this reinforces cultural stereotypes rather than explicating them. Liang Huan, a producer who worked with hanmai performers, said in an interview, "Hanmai is China's version of African American music (i.e., hip hop)." ${ }^{18}$ This analogy works insofar as hip hop was the voice of (Black) youth from lower socioeconomic areas and hanmai is propagated mostly by lower-class males. The difference between hanmai and hip hop within the Chinese contexts largely lies within its styles rather than its methods of production - both genres rely on remix, secondary music production, improvisation (during live events), or written lyrics. As Amar (2018) shows, the history of Chinese hip hop began with a thriving "underground" with a tremendous amount of "subcultural capital" (Thornton 1995), while hanmai's origin was much humbler and akin to mainstream (i.e. the lower class) tastes in the sense that it originated from mainstream discos as opposed to the underground scene. Before the ban on both hip hop and hanmai (Amar 2018), there was a cultural war between the two camps - a class war in Liang's words (hanmai represents the lower class and hip hop represents the middle class). Labelling both camps "subcultures" obscures the tension and value judgement entrenched in class politics and their struggle against their own versions of "the perpetual absent (...) the mainstream" (Thornton 1995: 17).

\section{Ge Zhang, a digital anthropologist, recently completed his PhD thesis on livestreaming media with the Digital Ethnography Research Centre at RMIT University (playbourer@outlook.com).}

I Jian Xu is a lecturer in Communication in the School of Communication and Creative Arts at Deakin University, with research interests in China's internet governance and digital youth culture. 


\section{References}

AMAR, Nathanel. 2018. "'你有 freestyle 嗎?' (Do you freestyle?) The Roots of Censorship in Chinese Hip-hop." China Perspectives 1-2(113): 107-14.

CAO, Yifan 曹一帆。2013. “幻覺時代的底層創傷與自我救贖: “帛絲” 現象的文化闡釋” (Huanjie shidai de diceng chuangshang yu ziwo jiushu: "diaosi" xianxiang de wenhua chuanshi, Grassroots trauma and self-redemption in the era of illusion: Cultural interpretation of "diaosi" phenomenon). 人文與社会 (Renwen yu shehui), 27 January. http://wen.org. cn/modules/article/view.article.php/3718 (accessed on 20 March 2019).

DAVIS, Deborah S. (ed.). 2000. The Consumer Revolution in Urban China. Berkeley: University of California Press.

FARRER, James. 2000. "Dancing through the Market Transition: Disco and Dance Hall Sociability in Shanghai." In Deborah S. Davis (ed.), The Consumer Revolution in Urban China. Berkeley: University of California Press. 226-49.

FIELD, Andrew D. 2008. "From D.D.'s to Y.Y. to Park 97 to Muse: Dance Club Spaces and the Construction of Class in Shanghai, 1997-2007." China: An International Journal 6(1): 18-43.

FIELD, Andrew D., and James FARRER. 2018. "China's Party Kings: Shanghai Club Cultures and Status Consumption, 1920s-2010s." In Dorothy J. Solinger (ed.), Polarized Cities: Portraits of Rich and Poor in Urban China. Lanham: Rowman \& Littlefield. 127-47.

GAO, Xiang 高翔. 2018. “爽文'為什麼這麼“爽”: 剖析 2018 熱播大 劇的快感機制和審美幻覺" ("Shuangwen" weishenme zheme "shuang": Pouxi 2018 jiabo daju de kuaigan jizhi he shenmei huanjue, Why "shuangwen" "feels so good": Analysis of the pleasure mechanism and aesthetic illusion of 2018 popular TV dramas). http://wemedia.ifeng. com/76327109/wemedia.shtml (accessed on 20 March 2019).

LIU, Yan 劉岩. 2015. “東北人不是黑社會” (Dongbeiren bushi heishehui, The Northeast is not a gangland). 文化研究 (Wenhua yanjiu, Cultural Studies) 22: 162-71.

LIU, Yan 劉岩. 2018. “新世紀東北喜劇的師/ 父表述與青年主體 再生產" (Xinshiji Dongbei xiju de shi/fu biaoshu yu gingnian zhuti zaishengchan, The expression of master/father and reproduction of youth subjectivity in Northeast comedy in the new century). http://old. cul-studies.com/index.php? $m=$ content\&c=index\&a=show\&catid=39\& id=1728 (accessed on 21 March 2019).

THORNTON, Sarah. 1995. Club Cultures: Music, Media and Subcultural Capital. Cambridge, UK: Polity Press.

WANG, Yuxi. 2017. "Globalization of Chinese Online Literature: Understanding Transnational Reading of Chinese Xuanhuan Novels Among English Readers." Inquiries Journal 9(12). http://www. inquiriesjournal.com/articles/1716/globalization-of-chinese-onlineliterature-understanding-transnational-reading-of-chinese-xuanhuannovels-among-english-readers (accessed on 13 March 2019).

WU, Yuen-wai. 2012. "A Journey Across Rivers and Lakes: A Look at the Untranslatable jianghu in Chinese Culture and Literature." $452^{\circ} \mathrm{F}$ Journal of Literary Theory and Comparative Literature 7: 58-71.

YANG, Guobin. 2009. The Power of the Internet in China: Citizen Activism Online. New York: Columbia University Press.

YU, Haiqing. 2017. "Beyond E-commerce: The Social Case of China's Digital Economy." China Perspectives 4(112): 3-8. 